\title{
Comparative Assessment of Gate Drive Control Schemes in High Frequency Converter
}

\author{
N. Z. Yahaya \\ Power \& Energy System Research \\ Cluster \\ Universiti Teknologi PETRONAS \\ Bandar Seri Iskandar 31750 Perak, \\ Malaysia \\ norzaihar_yahaya@petronas.com.my
}

\author{
K. M. Begam \\ Electronic Material \& Devices \\ Research Cluster \\ Universiti Teknologi PETRONAS \\ Bandar Seri Iskandar 31750 Perak, \\ Malaysia \\ mumtajbegam@petronas.com.my
}

\author{
M. Awan \\ Electronic Material \& Devices \\ Research Cluster \\ Universiti Teknologi PETRONAS \\ Bandar Seri Iskandar 31750 Perak, \\ Malaysia
}

\begin{abstract}
Several gate drive control schemes are simulated and the results show that the Fixed Duty ratio (FDR) can help drive synchronous rectifier buck converter (SRBC) correctly with low dead time and hence reduce body diode conduction loss. Even though FDR is prone to cross-conduction effects, the design is simple. Apart from that, Adaptive Gate Delay (AGD) and Predictive Gate Delay (PGD) control schemes have also shown high level of efficiency. However, AGD generates more losses. This makes PGD preferable in achieving a highly efficient converter of more than $82 \%$ in spite of the advantage in FDR and AGD schemes.
\end{abstract}

Keywords-gate drive control; high frequency; PSpice simulation; synchronous rectifier buck converter

\section{INTRODUCTION}

Many control schemes in gate driver for DC-DC converters have been introduced back in the 1990s. They include digital and also analog controls. In 1997, pulse based dead time, $T_{D}$ compensator (PBDTC) was introduced [1] where the switching times were modified to compensate $T_{D}$ so that output voltage, $v_{o}$ can be properly controlled in magnitude. In addition, it can adjust symmetric Pulse Width Modulator (PWM) pulses to correct voltage distortion. This replicates the fixed delay implementation. Some other literatures have discussed different methods in details $[2,3]$.

On the other hand, in recent development, several analog techniques have been developed to ensure "break before make" operation. They are the Fixed "dead time" or Fixed Duty Ratio (FDR), Adaptive Gate Delay (AGD) and Predictive Gate Delay (PGD). Each of them has its own characteristics, advantages and drawbacks which provide information for the suitability and cost effective gate driver design.

\section{A. Fixed Duty Ratio (FDR)}

Fixed Duty Ratio is the first PWM controller for synchronous rectifier buck converter (SRBC) circuit. The advantage of this technique is that it has a simple control circuit with lower voltage stress $[4,5]$. However, this scheme requires the $T_{D}$ to be provided long enough to cover the entire applications so that no cross conduction will occur. A lengthy
$T_{D}$ would reduce the converter efficiency by allowing the body diode to conduct.

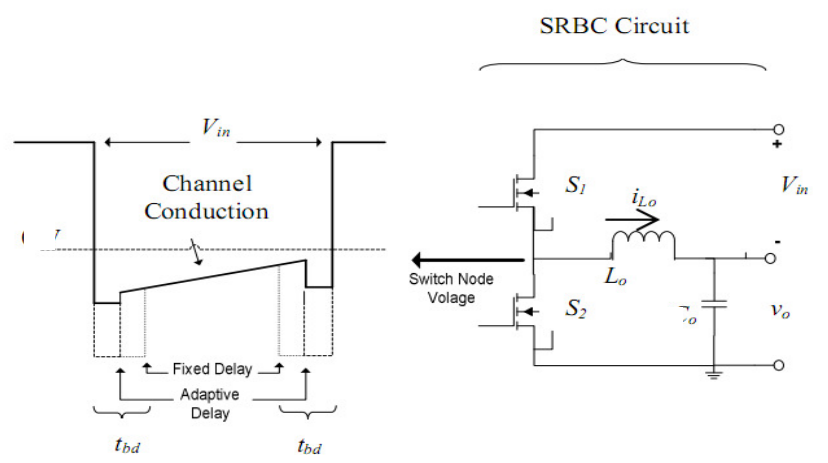

Fig. 1. Switch Node Waveform of SRBC

Figure 1 shows typical switch-node voltage waveform of SRBC. It shows the relative effects of FDR and AGD control schemes on body diode conduction time, $t_{b d}$. Theoretically, FDR scheme in general, produces a longer $t_{b d}$ eventually reducing the channel conduction time. However, a precise timing control could solve this issue. During $t_{b d}$, the inductor current, $i_{L o}$ will flow from ground through the body diode of switch $S_{2}$ and $L_{o}$ resulting the voltage drop across body diode which leads to the reduction in the efficiency of power conversion [6].

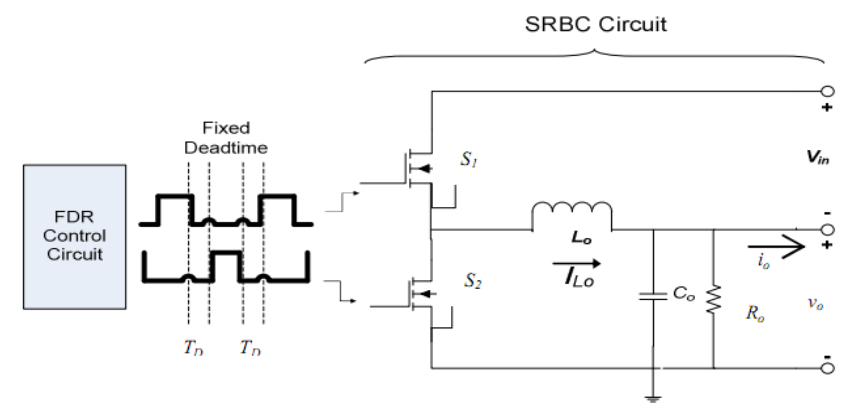

Fig. 2. Block Diagram of FDR Scheme with SRBC 
Figure 2 shows the block diagram of FDR control circuit integrated with SRBC circuit. The input signal produced by the driver circuit has $T_{D}$ application between switches. In addition, the efficiency of FDR technique also varies with different type of MOSFETs' ambient temperature and with lot-to-lot variation of the $T_{D}$ delay during manufacturing [7].

\section{B. Adaptive Gate Delay (AGD)}

Figure 3 shows the Adaptive Gate Delay (AGD) control scheme. This second generation gate driver control scheme was introduced to overcome the limitation in the FDR. It uses a control loop that includes a digital delay line where it senses the drain to source voltage, $v_{d s}$ of the $S_{2}$ and adjusts the digital delay line according to the amount of delay that should be applied to turn on $S_{2}$. Consequently, $S_{2}$ is turned on only when the switch node voltage equals to zero [8].

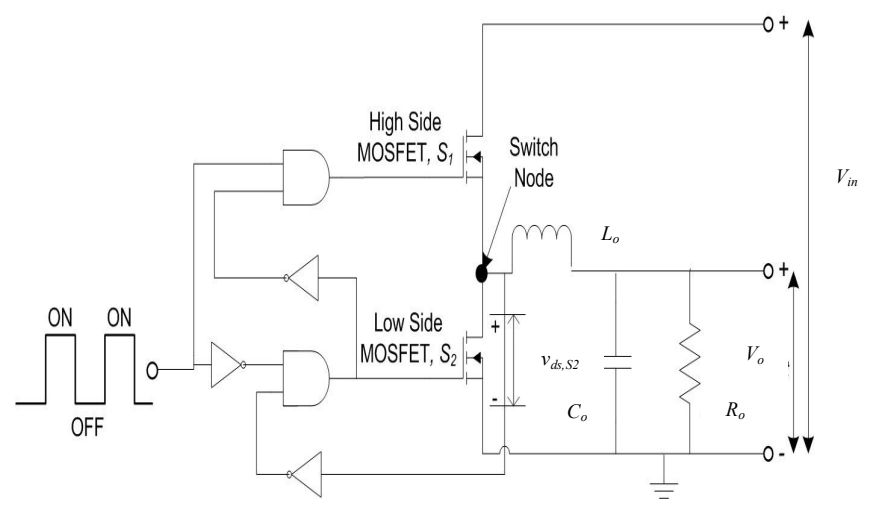

Fig. 3. Adaptive Gate Delay Control Scheme

The advantage of using this control scheme is that the adjustment of the delay can be made adaptively according to the type of MOSFET used. However, there is a disadvantage that comes from this control scheme. The variation of body diode conduction time interval may not easy to predict. This is due to the logic components used as the feedback circuit. Each of the components has its own propagation delay which may indirectly increase the $T_{D}$ between the pulses.

\section{Predictive Gate Delay (PGD)}

Since both FDR and AGD schemes have limitations, the Predictive Gate Delay (PGD) control scheme was then introduced. It is a combination of a predictive circuit integrated with PWM where it has the ability to vary the $T_{D}$ from time to time according to the feedback signal. The predictive time is shown in Figure 4. Here, the next $T_{D}, T_{D[n+1]}$ can be predicted and minimized based on the feedback.

PGD uses feedback loop as shown in Figure 5 in order to reduce the $T_{D}$ until it reaches near zero [9]. The predictive circuit will sense a signal (it can be in the form of Voltage or Current) from the SRBC Circuit.

Table I shows the summary of all three gate driver control schemes for SRBC circuits. Even though FDR is not suitable, it has the simplest configuration and easy to drive the SRBC. The only issue is that the $T_{D}$ has to be provided longer. However, this is not true since simulation results proved otherwise [10], the details of which are presented in Results and Discussions section. The data in the table gives the advantages and disadvantages of different control schemes so that the choice of the design can easily be made based on cost, component count and simplicity.

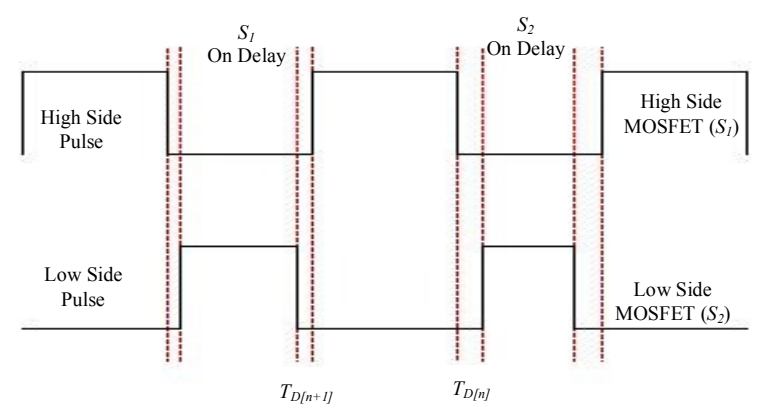

Fig. 4. Predictive Timing

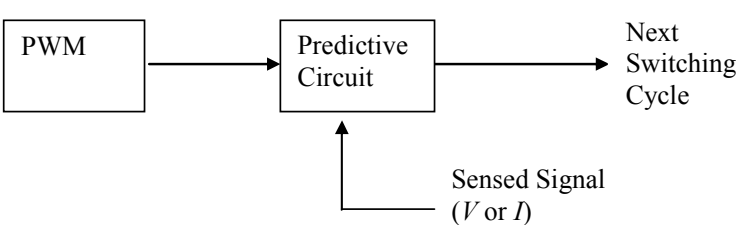

Fig. 5. PGD Scheme Block Diagram

TABLE I. ADVANTAGES AND DISADVANTAGES OF GATE DRIVE CONTROL SCHEMES

\begin{tabular}{|c|c|c|}
\hline Fixed Duty Ratio & Adaptive Gate Delay & Predictive Gate Delay \\
\hline $\begin{array}{l}\text { - constant, pre-set } \\
\text { delays for turn-off to } \\
\text { turn-on intervals } \\
\text { - simple in design } \\
\text { - efficiency varies with } \\
\text { MOSFET types and } \\
\text { ambient temperature } \\
\text { - Need to make delay } \\
\text { long enough to cover } \\
\text { entire application. }\end{array}$ & $\begin{array}{l}\text { - variable delays based } \\
\text { on volatage sensed on } \\
\text { current switching cycle } \\
\text { - uses state information } \\
\text { from power stage to } \\
\text { control turn-on of two } \\
\text { gate drivers and set } T_{D} \\
\text { - increases body diode } \\
\text { conduction time caused } \\
\text { by delay in cross } \\
\text { coupling loops } \\
\text { - unable to compensate } \\
\text { for delay to charge } \\
\text { MOSFET gate to } \\
\text { threshold level } \\
\text { - difficult to determine } \\
\text { whether } S_{2} \text { is off }\end{array}$ & $\begin{array}{l}\text { - uses information from } \\
\text { current switching cycle } \\
\text { to adjust delays to be } \\
\text { used in next cycle } \\
- \text { can prevent body } \\
\text { diode from being } \\
\text { forward biased and } \\
\text { hence cross conduction } \\
\text { - increases power } \\
\text { savings when MOSFET } \\
\text { is turned on } \\
\text { - minimizes reverse } \\
\text { recovery loss in } S_{l} \text { body } \\
\text { diode. } \\
\text { - tight layout regulation } \\
\text { requirement }\end{array}$ \\
\hline
\end{tabular}

\section{METHODOLOGY}

In this part of work, dual-channel function generators are again used to fix the pulse widths and $T_{D}$ of $Q_{1}$ to $Q_{4}$ switches for Fixed Duty Ratio (FDR) scheme to proposed dual-channel Resonant Gate Drive (RGD) circuit as shown in Figure 6 [10]. On the other hand, a set of combinational discrete components and transistor-transistor logic (TTL) gates are employed for the generation of Adaptive Gate Delay (AGD) and Predictive Gate 
Delay (PGD) schemes. All three schemes are compared to determine the effectiveness in terms of switching loss, output power distribution, body diode conduction loss and efficiency of the converter. Figure 7 and Figure 8 show the proposed AGD and PGD schemes respectively.

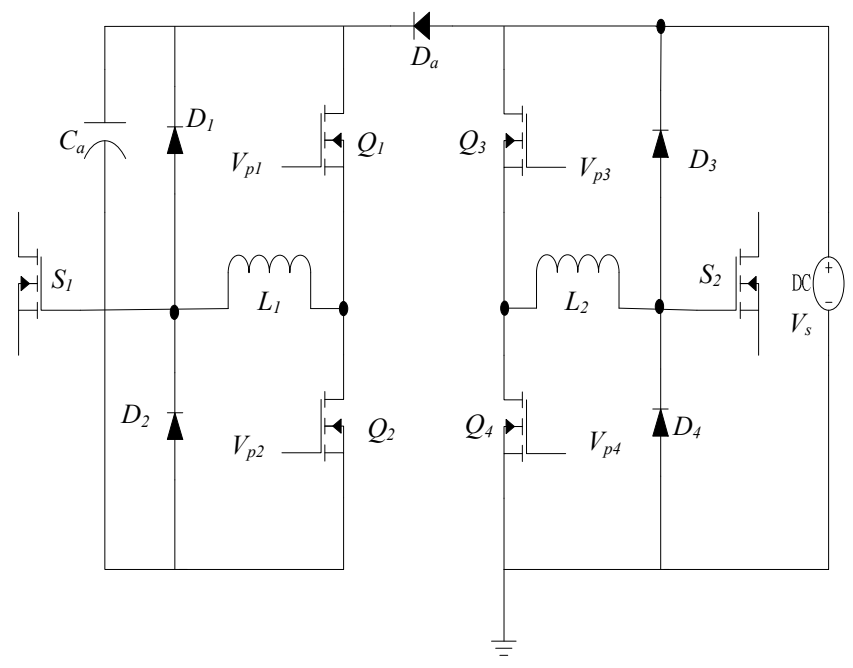

Fig. 6. Proposed Dual-Channel Gate Drive Circuit

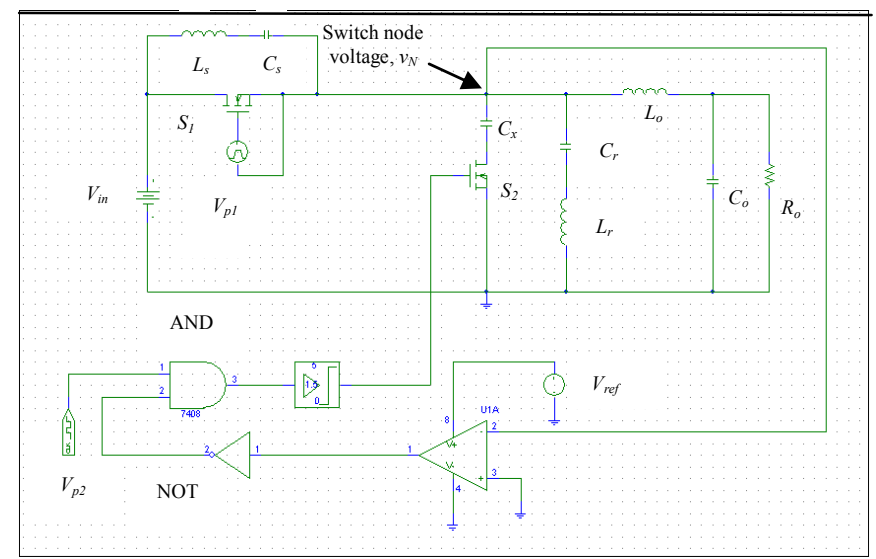

Fig. 7. Proposed Adaptive Gate Delay Scheme

The digital control block is included in the AGD scheme for the proposed SRBC circuit shown in Figure 7. In this scheme, $S_{1}$ is applied with a fixed PWM signal. $S_{2}$ switch is actually controlled by the scheme. Here, the node switch voltage is first captured and compared with the reference voltage, $V_{\text {ref. }}$. The digital clock will then be fed to the AND gate so that when the clock triggers with input $1, S_{2}$ switch will not turn on until node voltage is zero. The $T_{D}$ is measured along side with the body diode conduction time of $S_{2}$. As a result, the conduction loss, $P_{C O N D}$, body diode conduction loss, $P_{B D}$ and total switching loss, $P_{s w}$ can be calculated. The digital delay line settings are shown in Table II.
TABLE II. DIGITAL DELAY LINE SETTINGS

\begin{tabular}{|c|c|}
\hline Parameters & Value \\
\hline \hline Delay (ns) & 340 \\
\hline On Time (ns) & 645 \\
\hline Off Time (ns) & 355 \\
\hline Start value & 0 \\
\hline Opposite Value & 1 \\
\hline
\end{tabular}

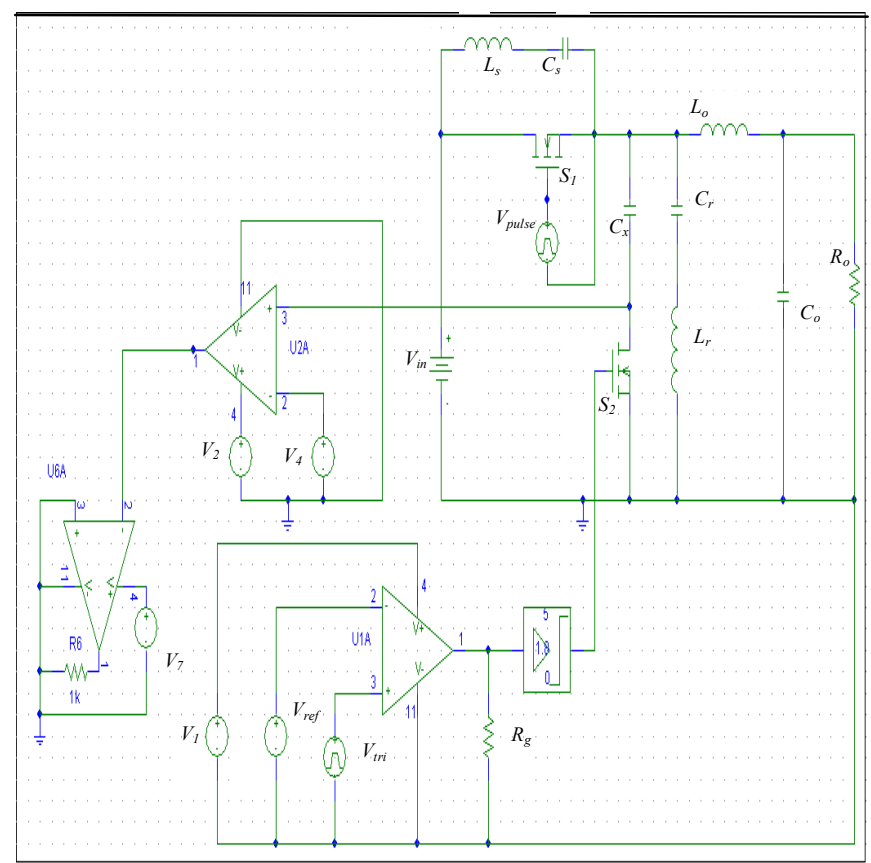

Fig. 8. Proposed Predictive Gate Delay Scheme

On the other hand, in PGD control scheme as shown in Fig 8 , the PWM technique using comparator is used where an equal pulse width will be generated from the comparison between the triangular waveform, $V_{t r i}$ and a reference voltage, $V_{r e f}$. The comparator will produce an output voltage each time $V_{\text {tri }}$ goes above $V_{\text {ref: }}$ In this work, the pulse width will be varied by adjusting $V_{\text {ref }}$ in between $0.2 \mathrm{~V}$ and $0.8 \mathrm{~V}$, to find out the capability of $T_{D}$ reduction in SRBC circuit.

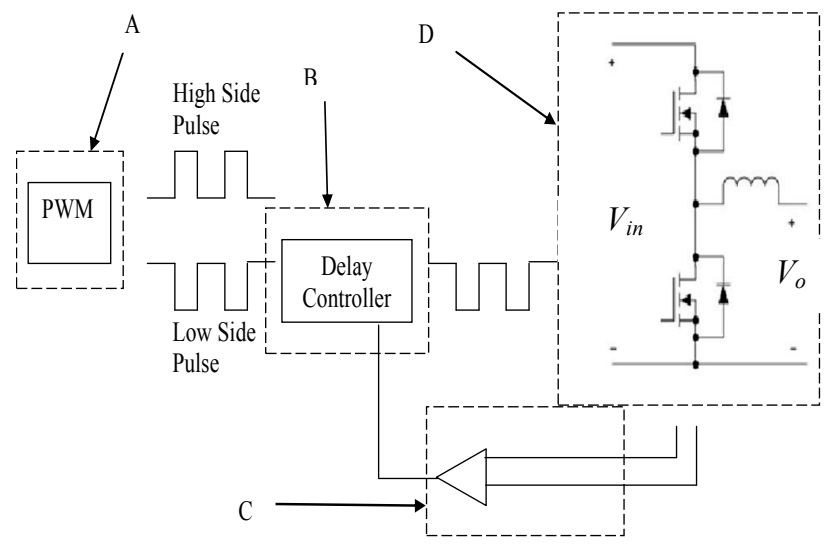

Fig. 9. Block Diagram of PGD Control Scheme 
The Block Diagram of the PGD is shown in Figure 9. Note that it is constructed from several circuits constituting PWM circuit (A), Delay Controller Circuit (B), Circuit to sense the body diode conduction (C), and SRBC Circuit (D). The PWM circuit (A) will generate the pulse that is used to turn on and off the MOSFET. The high side pulse will directly be used to drive $S_{1}$. The low side pulse will be the input of the delay controller (B) before it drives the $S_{2}$. Circuit (C) will perform the feedback operation and generate output signal to the delay controller. The operating details of block B and C are described below.

\section{Delay Controller Circuit}

The delay controller circuit will adjust the low side pulse before the output drives the $S_{2}$. The adjustment is based on the prediction concept where the width of the pulse will be adjusted by the controller according to the feedback signal it receives. From Figure 10, the $D[n]$ pulse is currently turned on the $S_{2}$. During this turn-on period, the feedback circuit will sense the conduction at $S_{2}$ due to the inductive load and it will generate a signal to the Delay Controller. Based on this signal, the controller will make an adjustment for the next pulse, $D[n+1]$ so that the dead time, $T_{D[n+1]}$ for next switching cycle can be minimized while preventing the cross conduction.

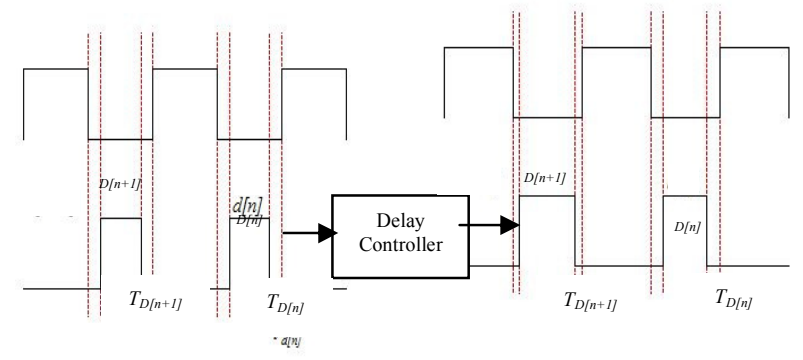

Fig. 10. Adjustment of Pulse Width Using Delay Controller

The adjustment made by the controller can be either to maximize or minimize the pulse width. Note that the dead time for $T_{D[n+1]}$ is adjusted by the delay controller. The adjustment of the pulse width can be done by varying the reference voltage, $V_{\text {ref. }}$ So, the delay controller will be fed to the reference voltage. It has the ability to vary the reference voltage according to the received input from the feedback circuit. Figure 11 illustrates how the pulse width can be adjusted based on the feedback circuit.

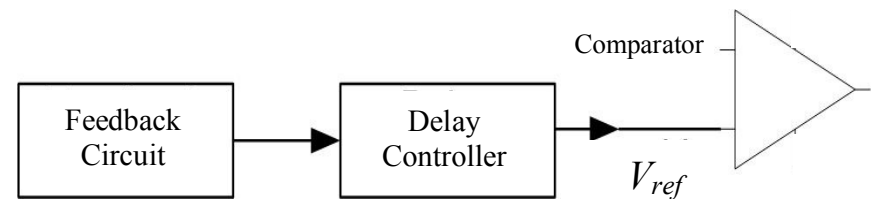

Fig. 11. Operation of Delay Controller

This is a circuit which the feedback operation is performed. The output generated from this circuit will be used as the input for the Delay Controller. During the high side pulse transition from HIGH to LOW, the comparator will sense the $v_{d s}$ of $S_{2}$. If body diode conduction is detected, the comparator will generate HIGH output and the delay controller will reduce the delay of low side pulse for the next switching cycle. If the comparator output generates a LOW output, the delay controller will increase the delay for the next switching cycle of $S_{2}$. As long as the SRBC operates, this shifting process will continuously occur to avoid the cross conduction while ensuring the $T_{D}$ delay introduced is small.

The feedback circuit will be received by the delay controller. Based on the signal received, the delay controller will adjust the $V_{\text {ref. }}$. Since the width of the pulse generated depends on the comparison between the $V_{t r i}$ and $V_{r e f}$, the variation in $V_{r e f}$ will change the $T_{D}$ between the pulses accordingly. The parameter setting for $V_{t r i}$ and $V_{\text {ref }}$ are given in Table III and Table IV respectively. Using the required frequency of $1 \mathrm{MHz}$, the frequency of the $V_{t r i}$ must also be same. As previously mentioned, the duty ratio, $D$ of $S_{1}$ is determined to be $20 \%$.

TABLE III. PARAMETER SETTINGS FOR $V_{t r i}$

\begin{tabular}{|c|c|}
\hline Parameters & Value \\
\hline Max Voltage, $V_{l}$ & 0 \\
\hline Min Voltage, $V_{0}$ & 1 \\
\hline Rise Time, $t_{r}$ & $0.5 \mu \mathrm{s}$ \\
\hline Fall Time, $t_{f}$ & $0.5 \mu \mathrm{s}$ \\
\hline
\end{tabular}

TABLE IV. PARAMETER SETTINGS FOR $V_{\text {pulse }}$

\begin{tabular}{|c|c|}
\hline Parameters & Value \\
\hline Max Voltage, $V_{l}$ & $5 \mathrm{~V}$ \\
\hline Min Voltage, $V_{0}$ & $0 \mathrm{~V}$ \\
\hline Rise Time, $t_{r}$ & $5 \mathrm{~ns}$ \\
\hline Fall Time, $t_{f}$ & $5 \mathrm{~ns}$ \\
\hline Time Delay, $t_{d}$ & $893 \mathrm{~ns}$ \\
\hline Pulse Width, $P W$ & $200 \mathrm{~ns}$ \\
\hline Time Taken for a Complete Cycle, $P E R$ & $1 \mu \mathrm{s}$ \\
\hline
\end{tabular}

The steady-state simulation analysis is repeated with different $V_{\text {ref }}$ values in order to investigate the effect in $T_{D}$ on SRBC circuit's performance. The study on the $P_{C O N D}-P_{B D}$ and $T_{D}-t_{b d}$ relationships with respect to $V_{r e f}$ are also carried out in addition to switching related losses in the converter.

\section{RESULTS AND DISCUSSIONS}

FDR, AGD and PGD control schemes are investigated to determine the feasibility in the reduction of SRBC's switching loss. In FDR scheme, the proposed dual-channel gate driver is applied directly to the converter. As for AGD and PGD control schemes, each of them is configured to connect the gate terminals of $Q_{4}$ and $S_{2}$ respectively. Then, the simulated results are compared and analyzed. 


\section{A. Comparison between FDR and AGD Control Schemes}

Table $\mathrm{V}$ shows the comparison in the analysis of FDR and AGD circuit operations. The initial study concentrates on the AGD scheme which was applied directly to the gate terminal of $Q_{4}$ (AGD- $Q_{4}$ ) in the proposed RGD circuit as shown in Figure 12 below. It is found that the implementation of AGD- $Q_{4}$ does not show significant improvement in SRBC except for the $V_{o}$ compared to FDR. When AGD- $Q_{4}$ is used, this adds up the $S_{2}$ body diode conduction time caused by the delay in cross coupling loops during $T_{D}$ detections in $Q_{3}-Q_{4}$ and $S_{1}-S_{2}$. As a result, $S_{2}$ will take a longer time to conduct. Moreover, the proposed AGD- $Q_{4}$ scheme requires a precise control on gate charge compensation delay of the switch. Otherwise, this may result in higher switching loss as measured of $2.52 \mathrm{~W}$, which is more than $7 \%$ higher than FDR.

The switching power loss is measured to be higher in AGD$S_{2}$ as shown in Figure 7 compared to AGD- $Q_{4}$ (Figure 12). This is due to the impact of $C_{x}$ in the converter which prolongs the detection of $T_{D}$ by the controller and hence reduces the efficiency. When comparing with FDR, their switching losses have increased by more than $7 \%$ and $24 \%$ respectively.

Therefore, this clearly indicates that using the proposed dual-channel RGD may help solve issues related to $T_{D}$, reduce conduction loss to $68.30 \mathrm{~mW}$ and hence switching loss. In other words, by applying the digital delay control directly to $S_{2}$ will not give much advantage in converter performance. This is the remarkable finding where the proposed stand-alone dualchannel RGD network can generate better loss savings in the converter.

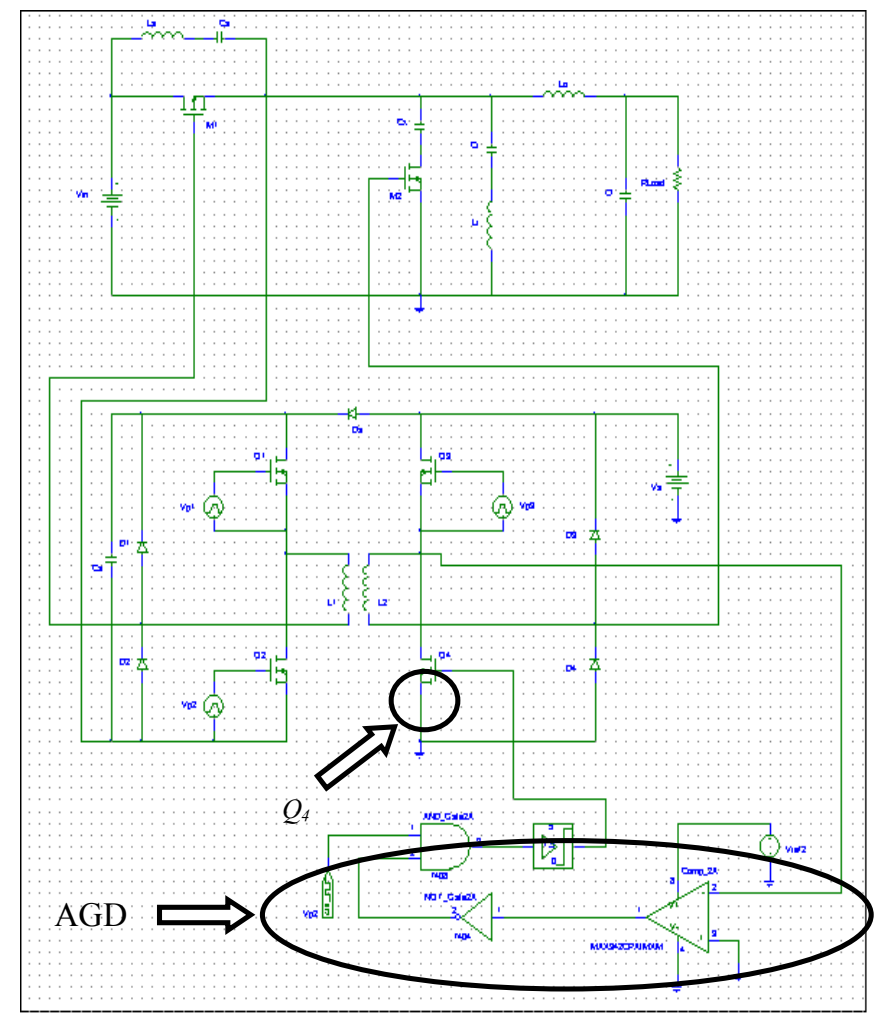

Fig. 12. RGD Circuit with AGD Control at $\mathrm{Q}_{4}$ Switch
TABLE V. FDR, AGD- $Q_{4}$ AND AGD- $S_{2}$ ANALYSIS FOR $D=20 \%$

\begin{tabular}{|l|l|l|l|l|l|}
\hline $\begin{array}{c}\text { Parameters } \\
\text { Analyzed }\end{array}$ & FDR & AGD- $\boldsymbol{Q}_{4}$ & $\begin{array}{c}\text { \% } \Delta \text { to } \\
\text { FDR }\end{array}$ & AGD- $\boldsymbol{S}_{2}$ & $\begin{array}{c}\text { \% } \boldsymbol{\Delta} \text { to } \\
\text { FDR }\end{array}$ \\
\hline \hline$V_{o}(\mathrm{~V})$ & 10.18 & 10.41 & 2.21 & 10.27 & 0.88 \\
\hline$I_{L o}(\mathrm{~A})$ & 1.51 & 1.27 & 15.89 & 1.28 & 15.23 \\
\hline$t_{b d}(\mathrm{~ns})$ & 24 & 27 & 11.11 & 28 & 14.28 \\
\hline$P_{C O N D}(\mathrm{~mW})$ & 68.30 & 86.90 & 21.40 & 87.40 & 21.85 \\
\hline$P_{B D}(\mathrm{~mW})$ & 25.73 & 26.11 & 1.46 & 28.62 & 10.10 \\
\hline$P_{S w}(\mathrm{~W})$ & 2.33 & 2.52 & 7.54 & 3.09 & 24.6 \\
\hline
\end{tabular}

\section{B. FDR and PGD Control Schemes}

The simulation of PGD control scheme is carried out based on the variation of $V_{r e f}$ as shown in Figure 8 and it is applied directly to the gate of $S_{2}\left(\mathrm{PGD}-S_{2}\right)$ in the proposed SRBC circuit through delay controller. The simulation data are presented in Table VI. From the variation of $V_{\text {ref }}$ in the PGD- $S_{2}$ control block, the SRBC switching losses in both $S_{1}$ and $S_{2}$ are measured. As $V_{\text {ref }}$ is decreased from $0.8 \mathrm{~V}$ to $0.27 \mathrm{~V}$, all parameter values except $i_{L o}$ reduces with respect to $T_{D}$. Then once $V_{\text {ref }}$ is below $0.27 \mathrm{~V}$, the results are no longer valid since $T_{D}$ is negative. It is also found that low switching losses lie between $0.27 \mathrm{~V}$ and $0.3 \mathrm{~V}$. If $V_{\text {ref }}$ is applied with less than 0.27 $\mathrm{V}$, the pulses will overlap each other and lead to crossconduction. A high $V_{\text {ref }}$ yields a greater output voltage which is favorable in the design but the body diode conduction loss will increase resulting in high total switching loss in the circuit.

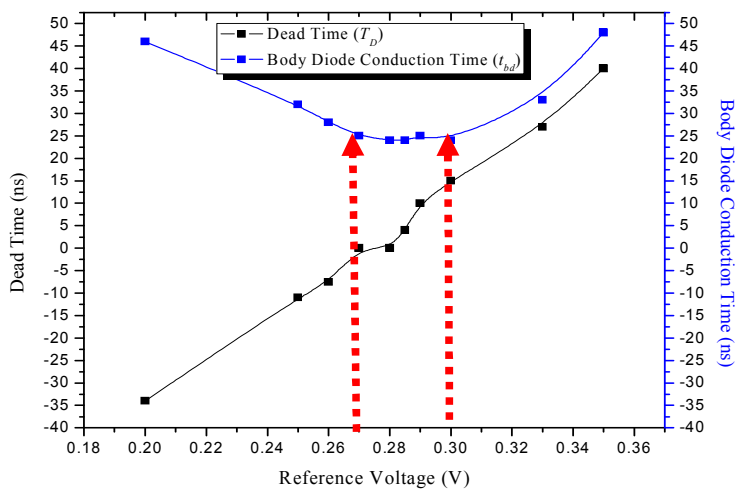

Fig. 13. Relationship between $T_{D}$ and $t_{b d}$ Vs $V_{\text {ref }}$

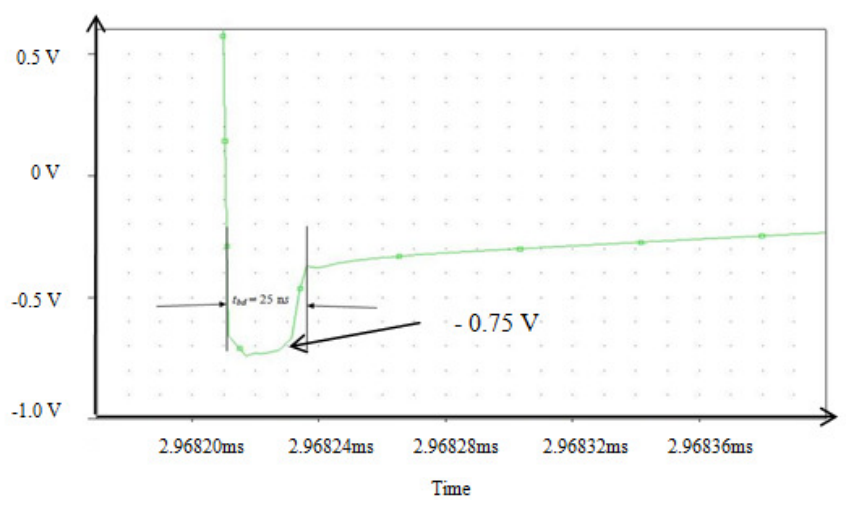

Fig. 14. Body Diode Conduction Time at $V_{\text {ref }}$ of $0.29 \mathrm{~V}$ 
TABLE VI. SWITCHING LOSS MEASUREMENT ADOPTING PGD- $S_{2}$ CONTROL SCHEME FOR $D=20 \%$

\begin{tabular}{|c|c|c|c|c|c|c|c|c|c|}
\hline $\begin{array}{c}\boldsymbol{V}_{\text {ref }} \\
(\mathbf{V})\end{array}$ & $\begin{array}{c}\boldsymbol{V}_{\boldsymbol{o}} \\
(\mathbf{V})\end{array}$ & $\begin{array}{c}\boldsymbol{I}_{\boldsymbol{L o}} \\
(\mathbf{A})\end{array}$ & $\begin{array}{c}\boldsymbol{T}_{\boldsymbol{D}} \\
(\mathbf{n s})\end{array}$ & $\begin{array}{c}\boldsymbol{t}_{\boldsymbol{b d}} \\
(\mathbf{n s})\end{array}$ & $\begin{array}{c}\boldsymbol{P}_{\boldsymbol{C O N D}} \\
(\mathbf{m W})\end{array}$ & $\begin{array}{c}\boldsymbol{P}_{\boldsymbol{B D}} \\
(\mathbf{m W})\end{array}$ & $\begin{array}{c}\boldsymbol{P}_{\boldsymbol{s w}, \boldsymbol{S} \boldsymbol{1}} \\
(\mathbf{W})\end{array}$ & $\begin{array}{c}\boldsymbol{P}_{\boldsymbol{s w}, \boldsymbol{S} \mathbf{}} \\
(\mathbf{W})\end{array}$ & $\begin{array}{c}\boldsymbol{P}_{\boldsymbol{s w}, \boldsymbol{T o t a l}} \\
(\mathbf{W})\end{array}$ \\
\hline \hline 0.8 & 11.60 & 1.12 & 260 & 350 & 103.90 & 109.0 & 1.64 & 1.03 & 2.88 \\
\hline 0.6 & 11.23 & 1.25 & 170 & 220 & 115.65 & 77.0 & 1.96 & 1.42 & 3.34 \\
\hline 0.4 & 10.23 & 1.31 & 66 & 82.5 & 92.51 & 54.9 & 1.42 & 1.25 & 2.82 \\
\hline 0.35 & 10.41 & 1.48 & 40 & 48 & 81.15 & 48.8 & 1.61 & 1.20 & 2.94 \\
\hline 0.33 & 10.35 & 1.50 & 27 & 33 & 71.24 & 36.8 & 1.56 & 1.15 & 2.82 \\
\hline 0.3 & 10.24 & 1.52 & 15 & 24 & 68.27 & 24.6 & 1.16 & 1.10 & 2.35 \\
\hline 0.29 & 10.22 & 1.53 & 10 & 25 & 67.27 & 24.0 & 1.17 & 1.09 & 2.35 \\
\hline 0.285 & 10.11 & 1.54 & 4 & 24 & 62.43 & 23.5 & 1.15 & 1.10 & 2.33 \\
\hline 0.28 & 10.07 & 1.56 & 0 & 24 & 61.89 & 23.7 & 1.18 & 1.11 & 2.38 \\
\hline 0.27 & 10.02 & 1.58 & 0 & 27 & 60.25 & 23.2 & 1.20 & 1.15 & 2.43 \\
\hline 0.26 & 10.95 & 1.29 & -7.5 & 28 & 59.57 & 28.5 & 1.28 & 1.90 & 3.26 \\
\hline 0.25 & 11.89 & 0.98 & -11 & 32 & 66.93 & 30.7 & 1.32 & 2.35 & 3.76 \\
\hline 0.2 & 12.38 & 0.64 & -34 & 46 & 71.68 & 33.1 & 1.56 & 3.10 & 4.76 \\
\hline
\end{tabular}

Figure 13 explains that the $t_{b d}$ increases linearly with $T_{D}$ starting from $V_{\text {ref }}$ at $0.27 \mathrm{~V}$. The faster free-wheeling $i_{L o}$ flows into the body diodes during $T_{D}$, the lower power loss in the converter will be. For instance, at $V_{\text {ref }}=0.29 \mathrm{~V}$, the $t_{b d}$ is measured $25 \mathrm{~ns}$ with $-0.75 \mathrm{~V}$ overshoot indicating the duration of on-state conduction of body diode as shown in Figure 14. Therefore, $t_{b d}$ has to be minimized and this can be realized by reducing $T_{D}$. However, due to the fact that $T_{D}$ cannot be negative, the best applicable $V_{\text {ref }}$ is $0.28 \mathrm{~V}$ to achieve the lowest $t_{b d}$.

In Figure 15, the $P_{C O N D}$ and $P_{B D}$ losses are minimum at $V_{\text {ref }}$ $=0.27 \mathrm{~V}$. Here, when $V_{\text {ref }}$ is less than $0.27 \mathrm{~V}$ or greater than 0.3 $\mathrm{V}$, these losses will increase. It is also seen in the figure that the MOSFET's conduction loss is slightly higher at $V_{\text {ref }}=0.3 \mathrm{~V}$ due to the presence of $T_{D}=15 \mathrm{~ns}$. The role of the controller is to minimize the $T_{D}$ for the lowest possible $P_{C O N D}$ by detecting it before $S_{2}$ can be turned on. However, this is valid only if $T_{D}$ is positive. The $t_{b d}$ is slightly higher at $V_{r e f}=0.27 \mathrm{~V}$ compared to $0.3 \mathrm{~V}$ because the high possibility of cross-conduction.

The next study looks at the application of PGD control scheme to the $Q_{4}$-switch (PGD- $Q_{4}$ ) of the proposed dualchannel RGD circuit. The process in determining the SRBC switching losses is similar to the PGD- $S_{2}$ implementation. Table VII gives the comparative assessments between PGD- $Q_{4}$ and PGD $-S_{2}$ for $V_{\text {ref }}=0.27 \mathrm{~V}$ and $T_{D}=0 \mathrm{~ns}$.

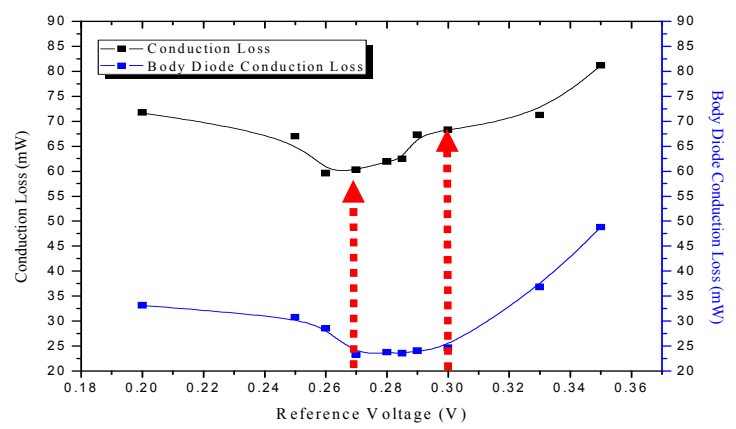

Fig. 15. Relationship between $P_{C O N D}$ and $P_{B D}$ Vs $V_{\text {ref }}$
TABLE VII. COMPARISON OF PGD- $Q_{4}$ AND PGD- $S_{2}$ FOR $V_{r e f}=0.27 \mathrm{~V}, D=20$ $\%$ AND $T_{D}=0 \mathrm{~ns}$

\begin{tabular}{|c|c|c|c|}
\hline $\begin{array}{c}\text { Parameters } \\
\text { Analyzed }\end{array}$ & PGD- $\boldsymbol{Q}_{4}$ & PGD- $\boldsymbol{S}_{2}$ & $\mathbf{\%} \boldsymbol{\Delta}$ \\
\hline \hline$V_{o}(\mathrm{~V})$ & 10.20 & 10.02 & 1.76 \\
\hline$I_{L o}(\mathrm{~A})$ & 1.56 & 1.58 & 1.27 \\
\hline$t_{b d}(n s)$ & 26 & 27 & 3.70 \\
\hline$P_{C O N D}(\mathrm{~mW})$ & 62.30 & 60.25 & 3.29 \\
\hline$P_{B D}(\mathrm{~mW})$ & 23.65 & 23.20 & 1.90 \\
\hline$P_{s w, S 1}(\mathrm{~W})$ & 1.25 & 1.20 & 4.00 \\
\hline$P_{s w, S 2}(\mathrm{~W})$ & 1.18 & 1.15 & 2.54 \\
\hline$P_{s w, T o t a l}(\mathrm{~W})$ & 2.52 & 2.43 & 3.57 \\
\hline
\end{tabular}

Table VII reveals the impact on utilizing the RGD network with PGD control block. The $P_{C O N D}$ is seen slightly higher in PGD- $Q_{4}$ scheme of $62.30 \mathrm{~mW}$ which gives a reduction in 3.29 $\%$ compared to PGD- $S_{2}$. Also, since the $T_{D}$ is assumed to be zero at $V_{\text {ref }}=0.27 \mathrm{~V}$, ideally, $P_{B D}$ can be minimized. However, this will slightly increase $t_{b d}$ compared to $V_{r e f}$ at $0.3 \mathrm{~V}$ and hence shoots up $S_{1}$ switching loss. In spite of this drawback, the PGD controller is still able to control and adjust $S_{2}$ gate signal and maintain $P_{C O N D}$ and $P_{B D}$ losses at low levels.

By introducing a small interval of $15 \mathrm{~ns} T_{D}$ as given in Table VIII, the issue in signal overlapping can be avoided. In fact, the PGD controller can have a longer safe time margin to detect the $T_{D}$ before $V_{g s, S 2}$ can be turned on. The application of non-zero $T_{D}$ may in turn give rise to higher $P_{C O N D}$ and $P_{B D}$. Remarkably, $S_{l}$ switching loss is reduced compared to $V_{\text {ref }}$ at $0.27 \mathrm{~V}$ leading to lower total switching loss for a shorter duration in $t_{b d}$. 
TABLE VIII. COMPARISON OF FDR AND PGD- $S_{2}$ AT $V_{r e f}=0.3 \mathrm{~V}$ FOR $D=20 \%$ AND $T_{D}=15 \mathrm{~ns}$

\begin{tabular}{|c|c|c|c|}
\hline $\begin{array}{c}\text { Parameters } \\
\text { Analyzed }\end{array}$ & FDR & PGD-S & \% $\boldsymbol{\Delta}$ \\
\hline \hline$V_{o}(\mathrm{~V})$ & 10.18 & 10.24 & 0.59 \\
\hline$I_{L o}(\mathrm{~A})$ & 1.51 & 1.52 & 0.65 \\
\hline$t_{b d}(n s)$ & 24 & 24 & - \\
\hline $\begin{array}{c}P_{C O N D} \\
(\mathrm{~mW})\end{array}$ & 68.30 & 68.27 & 0.04 \\
\hline$P_{B D}(\mathrm{~mW})$ & 25.73 & 24.60 & 4.39 \\
\hline$P_{s w, S 1}(\mathrm{~W})$ & 1.14 & 1.16 & 1.72 \\
\hline$P_{s w, S 2}(\mathrm{~W})$ & 1.10 & 1.10 & - \\
\hline$P_{s w, T o t a l}(\mathrm{~W})$ & 2.33 & 2.35 & 0.85 \\
\hline
\end{tabular}

In addition, the use of the proposed dual-channel RGD (FDR) circuit can also be considered as an independent gate drive control option to bias $S_{1}$ and $S_{2}$ gates. The total switching loss in FDR is only $0.85 \%$ lower than PGD- $S_{2}$. However, PWM signals have to be generated with precise control to avoid cross conduction even though it is known for its simplicity. From the evaluation, PGD- $S_{2}$ is found to be the best option for the gate drive control mechanism. Apparently all simulation results have indicated positive remarks and brought to successful analyses in the comparison of different PGD driving techniques with the FDR scheme.

\section{Efficiency Comparison}

The efficiency is measured based on the proposed SRBC circuit with fixed load and input values. The gate drive control schemes: AGD and PGD are applied to $Q_{4}$ and $S_{2}$ respectively in each case. It is observed in Figure 16 that the use of PGD control scheme gives a higher efficiency of more than $82 \%$ at $I_{L o}$ of 1.5 A compared to AGD and FDR. In addition, the application of AGD- $Q_{4}$ produces better efficiency compared to AGD- $S_{2}$ by only $2 \%$ because RGD helps control $V_{g s, Q 4}$ turn-on for the generation of $S_{2}$ pulses. This indicates the necessity of having gate drive circuit in SRBC. However, PGD control scheme does not require any intermediate RGD circuit to achieve high efficiency. The application of PGD- $S_{2}$ can reduce the switching loss effectively as $S_{2}$ gate can intelligently be adjusted and controlled with respect to the detection of $T_{D}$ in the circuit.

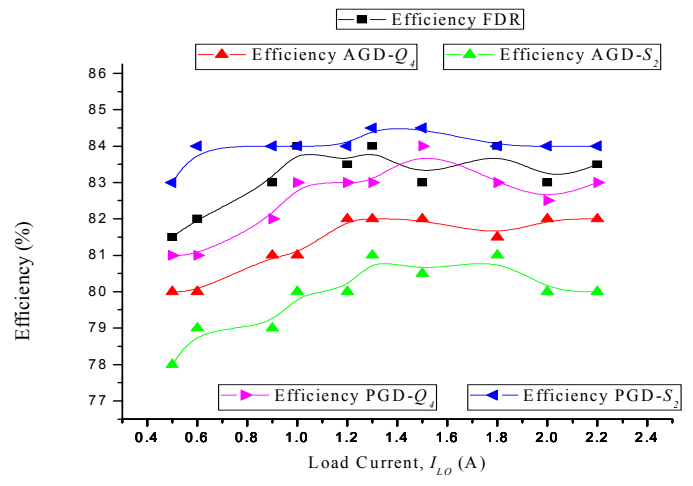

Fig. 16. Efficiency of Gate Drive Control Schemes Vs $I_{L o}$ for $D_{S l}=20 \%$, $D_{S 2}=75 \%$ and $T_{D}=15 \mathrm{~ns}$ on Proposed SRBC Circuit
In FDR scheme, the driving pulses given to $Q_{1}-Q_{4}$ switches can be precisely controlled by independent PWM generators. It is found that FDR scheme can also manage to cap the efficiency high of $83 \%$ which is comparable to PGD- $S_{2}$ implementation. Due to its simplicity, it can be considered since the complemented signals generated at the gates of $S_{1}$ and $S_{2}$ are easy to control and monitor in accordance with any design requirements.

\section{CONCLUSION}

As PGD scheme is concerned, the total switching loss has improved slightly by $1 \%$ compared to the FDR scheme which indicates the feasibility of the design. However, PGD is not easy to be implemented. It has been proven in the work that FDR can manage to sustain a low value of body diode conduction time even though there is a risk in shoot-through current due to its simplicity in design. The AGD and PGD schemes are beneficial to improve the gate driving loss but the design is complex. Comparatively, FDR scheme is easy to apply and eventually gives better advantages in converter's performance. Therefore, the stand-alone FDR control or a direct implementation of PGD- $S_{2}$ scheme can be chosen as an easy alternative in the design of high frequency SRBC circuit.

\section{ACKNOWLEDGMENT}

The authors would like to thank Universiti Teknologi PETRONAS, for providing financial support in publishing this work.

\section{REFERENCES}

[1] D. Leggate, R. J. Kerkman, "Pulse-Based Dead-Time Compensator for PWM Voltage Inverters" in IEEE $21^{\text {st }}$ Int. Conf. Ind. Electron., Contr. and Instr., USA, Vol. 1, pp. 474 - 481, 1995.

[2] K. Yamamoto, K. Shinohara, H. Ohga, "Effect of Parasitic Capacitance of Power Device on Output Voltage Deviation during Switching DeadTime in Voltage-Fed PWM Inverter" in Proc. Power Conv. Conf., Japan, Vol. 2, pp. 777 - 782, 1997.

[3] C. Jung-Soo, Y. Ji-Yong, L. Seung-Won, K. Young-Seok “A Novel Dead Time Minimization Algorithm of the PWM Inverter" in IEEE $34^{\text {th }}$ Annu. Meet. Ind. App. Conf., Vol. 4, pp. 2188 - 2193, 1999.

[4] T. Y. Ahn, H. J. Kim, K. Harada, "Fixed Frequency, Fixed Duty Ratio Controlled Forward ZVS-MRC Using A Saturable Core" in IEEE of $24^{\text {th }}$ Annu. Power Electron. Spec. Conf., pp. 551-557, 1993.

[5] T.Y. Ahn, H.J. Kim, K. Harada, "Fixed Frequency Forward ZVS-MRC Using A Saturable Core" in $15^{\text {th }}$ Int. Telecom. Energy Conf., Vol. 1, pp. 334-340, 1993.

[6] A. Chapuis, M. Hill, "Adaptive Delay Control Circuit for Switched Mode Power Supply”, U. S. Patent 6958592 B2, 2005.

[7] S. Mappus, "Predictive Gate Drive Boost Synchronous DC/DC Power Converter Efficiency” App. Rep. Texas Instruments SLUA281, 2003.

[8] M. L. Chiang, L. C. Fu, "Adaptive Control of Switched Systems with Application to HVAC System" in IEEE Int. Conf. Contr. Applications, pp $367-372,2007$

[9] J. S. Brown, "Method and Apparatus for Intelligently Setting Dead Time", U. S. Patent: 7098640 B2, 2006.

[10] N. Z. Yahaya, K. M. Begam, M. Awan "Design and Simulation of an Effective Gate Drive Scheme for Soft-Switched Synchronous Buck Converter" in IEEE 3rd Asia Int. Conf. Mod. \& Sim., pp. 751 - 756, 2009. 


\section{AUTHORS PROFILE}

Nor Zaihar Yahaya was born in Lumut, Malaysia. He went to the University of Missouri-Kansas City, USA to study electronics. He graduated with BSc in Electrical Engineering in 1996. After that he served 5 years in the industry in Malaysia. In 2002, he was awarded his MSc in Microelectronics from the University of Newcastle Upon Tyne, UK. He received his $\mathrm{PhD}$ from the Universiti Teknologi Petronas, Malaysia in 2011. His main teaching/research areas are the study of Power Electronics Switching Converters and Analog Power Devices.

K. M. Begam graduated in Physics from the Madras University, India in 1982. After graduation, she joined the post-graduate course in Physics with Electronics specialization and received her Masters Degree from the Bharathidasan University, India in 1984. Then she was working in various capacities at the P.S.N.A. College of Engg. \& Tech., affiliated to Anna University for 17 years. She came to Malaysia in the year 2000 and obtained her Doctorate from the Multimedia University for her work on Solid State Devices. Currently, she is attached with the University Teknologi PETRONAS as an Associate Professor in the Department of Electrical and Electronic Engr. Her research interest is in Lithium-ion batteries, hybrid power sources, Solid state devices, and Semiconductor sensors.

M. Awan received the B App Sc from USM, Penang, Malaysia, in 1980, the MSc (E) from University of New Brunswick, Fredericton. Canada, 1984, and the Ph.D from University of Southampton, England, 1991. He had worked as test engineer at Intel technology, Penang, prior to the post graduate study. $\mathrm{He}$ is an Associate Professor at the department of Electrical and Electronic Engineering, USM, until 2003. Currently, he is an Associate Professor at the Electrical and Electronic Engineering, Universiti Teknologi PETRONAS, Malaysia. He research interests include the design and implementation and verification of low power analog RF circuits and digital ICs. 